\title{
WOMEN AS EMOTIONAL ENTITIES IN THE HOSPITALITY SECTOR OF MAURITIUS. A CASE STUDY
}

\author{
RUGHOOBUR Soujata \\ University of Mauritius, Mauritius
}

\begin{abstract}
:
Emotions and feelings have always been part of human beings. Its use in the organisational context in order to achieve competitive advantage, that is, the management of emotions by female workers remains a matter of great debate. Hochschild through her book "The Managed Heart: Commercialisation of Human Feeling" in 1983 brought forward the concept of Emotional labour. This paper has attempted to explore areas where female workers are being employed to carry out emotional work and for this purpose a hotel in the eastern cost of Mauritius was chosen being part of the hospitality industry. The survey was conducted there so as to be able to gather quantitative information about this subject issue and a personal interview was also being carried out in order to obtain the opinions of the human resource manager on this concept as being a woman and a manager herself. A series of recommendations have been provided in order to encourage better treatment of women and make them happy employees.
\end{abstract}

Key words: emotional labour, women, hospitality sector

\section{Introduction}

"The Managed Heart: Commercialisation of Human Feelings" the seminal book of Hochschild published in 1983 has brought forward the concept and utilisation of emotions in the workplace. Today's economy is more geared towards the service industry, therefore exceeding customers' satisfaction on service excellence remains a differentiation power for businesses. The participation of women in the labour force since long time and their contribution to the economic success of a country has always been recognised. In today's businesses, women have been mostly associated with the managerial concept of emotion management. In order to shed light on the complexities of this issue, a hotel in the eastern coast of Mauritius was chosen as it has always been praised for its service quality. This research effort seeks to bring into focus emotional labour of women in the service sector and also exploring the reasons behind allocating them these tasks. It will also bring into limelight the realities of the world of work by exposing the capitalists' labour route where the private spheres of these women are being commercialised and thus leading to a number of negative 
consequences like alienation, emotional dissonance and health consequences amongst others.

\section{Literature review}

\subsection{Introduction}

Emotions and feelings help to differentiate one from others. Emotions in organisations have been heavily researched in the past few years and thanks to the rising service sector and the resultant drawing army frontline service workers who must create desirable, emotional climate and the resource base view of the firm that focuses on emotion as a valuable resource that has to be harnessed for gain in competitive advantage. Therefore, emotion management has become an arena where the inner selves of humans are being managed. This literature has placed women at the centre of this issue in the service industry to untangle the obscurity associated with emotion management and emotional labour as organisations have feelings and they are the sites for passion, love and hatred.

\subsection{What is Emotion Management?}

Since the past few decades, human emotions have been a subject of great debate. This topic itself is a vague, intensive and assorted one; yet academics and authors like Hochschild (1983) and Frijda et al (1991) have been able to explore this subject matter to a high level. Emotion management can be defined as the ways in which people manipulate their very own feelings and expressions and the ways in which they influence feelings of others. According to Hochschild (1983), emotion is a representative of the self and also a mediator that makes the proper association between what is being seen and also how one will react towards this situation keeping in mind what is supposed to be seen. She further argues that workers must firmly control their emotions while performing their tasks due to the expectation of their employers and also in order to provide a friendly service to customers. Organisational scholars opined that emotion management promote organisations however it can be detrimental to the welfare of the workers and the society as well on a long term basis (Waldron, 1994).

Conrad and Witte (1994) bring the concept of emotion management to another extreme as a beneficial factor to the employees, helping them to handle stress and evade negative contagion through the endorsement of their own emotional stability.

\subsection{Women as Principal Forms of Emotional Labour}

\section{Emotional Labour}

According to Wharton and Erickson (1993), "employers' efforts to shape workers' emotions and emotional displays have become an important focus of 
research in organisation". The word "shaping" in fact shows how workers are being managed or designed to fit into the organisational grid for better manoeuvring. Use of flamboyant quotes like "Service with a smile" is the most common type of work which involves the use of emotions which is termed as "Emotional Labour" by Hochschild (1983). Hochschild (1983) defines emotional labour as the "management of feeling to create a publicly facial and bodily display" which aspires to show that emotional labour is an entirety inner and outer bodily display. She furthers the concept as "This emotional labour requires one to induce or suppress feeling in order to sustain the outward countenance that produces the proper state of mind in others" and in the same line writers like James $(1884,1950,1994)$ puts emphasis that emotional labour is the act of managing one's emotions together with controlling the feelings of others. Emotion is being viewed as a valuable resource, mental strength and a type of energy which attract organisations. Hochschild (1983) also furthers this idea as a value exchange organism which the workers have to display in return of their pay. Isenbarger and Zemylas (2006) categorised emotional labour as a control between felt and displayed emotions. In this work light, Mann (2007) also illustrated the conflict between the real and displayed feelings. Hochschild (1983), through her work brought forward the dilemmas faced by women in the service sector by analysing the female flights attendants.

Nevertheless, Wharton (1993) demonstrated that women who are indulged in emotional work are rather more pleased compared to men in the same industry. This entails that possibly women are far better socialised entities and they are able to handle their emotions in the service work and this competitive advantage of them has made them one of the pillars of the service factory.

When emotional labour is being put in to practice, the notion of display rules must be brought into focus.

\section{Display Rules}

Display rules occupy a very important role for front liners while performing their tasks. These display rules are expected by them as positive feelings to be put on view (Rafaeli \& Sutton, 1987) in order to create the same energies on the customers. Ashforth and Tomiuk (2000) demonstrated the fact that even those service actors who identify firmly their required emotions will not always be able to feel what is truly expected from them. Instructions like "Put energy and enthusiasm into every guest interaction" or "Show a cheerful attitude at every table" are very common in employee handbooks. The use of companies policies, myths, stories by the companies are used as a manipulative tool so as to promote display rules so as to promote friendliness, courteousness from the employees to the customers and most importantly to manage their negative emotions towards customers.

In this work dimension, Pugh (2002) underlined the fact that women have the tendency to display more of positive and negative emotions when they have to counter service and due to this inclination women are engaged in more suppression of their emotions in order to stick on to the display rules. 
Display rules are usually being backed by the deep and surface acting as it is the backbone of the whole concept and Hochschild (1983) brought that into spotlight as to her opinion emotional labour is being carried out through these two ways.

\section{Deep and Surface Acting}

Deep and surface acting are two approaches that attempt to mutate feelings and both are false internally. These feelings cannot be modified at once as in both cases one must learn to get involved with his or her own feelings in order to craft their inner feelings or shape their outer appearance.

Deep acting is more concerned with manipulating inner feelings in order to meet the required displays. Rafaeli and Sutton (1987) has characterised deep acting as "faking in good faith". In other words, the intention behind deep acting is for the purpose to seem genuine to the audience.

Surface acting can be described as the "painting on" affective exhibition or even faking emotions of the facial expressions, voice tones and bodily movement. These emotions are just being presented in order to modify feelings or match expressions (Hochschild, 1983) which have been conceptualized by Rafaeli and Sutton (1987) as "faking in bad faith".

In fact both deep and surface acting attempts to "the display of expected emotions" (Ashforth and Humphrey, 1993) and it can be seen as "the act of expressing organizationally desired emotions during service transactions" (Morris and Feldman, 1996). Therefore in can be put forward that it is the employees' efforts to dynamically display socially and organisationally desired emotions when they are engaged in jobrelated relations. These emotional works are considered to be part of the normal work; each worker is supposed to be displaying positive feelings according to their job prescription. Moreover, the inconsistency that does exist while the services are being delivered must be taken into account as this activity is not a standard one.

Ashforth \& Humphrey (1993) earmarked the fact that it is not always that the workers show these positives energies and especially those who do not identify themselves with their given role. Grandey (2000) also marked down that some employees do not even know how to regulate their very own feelings when they are engaged in the deep acting process.

Conversely, writers such as Gross and John (2003) through their research have shown that it is the male employees who are more engaged in deep and surface acting compared to women as they tend to better suppress their emotions.

\subsection{Universal Division of Labour}

\section{History}

Times gone by are rich sources to understand the position and treatment of women in the society as they have always been subject of irony. Famous playwrights like Shakespeare portrayed women as "Frailty thy name is women" and this is a clear example how women were being viewed. Women have always been marginalised by 
the society itself as they were supposed to bear children and household chores. Friedl.E (1975) has stretched this process as the "Universal Division of Labour" which has limited the roles of females in the society.

Since the World War I and World War II, the role of women in society has known a drastic change as they started entering the labour market and there was a rise of women in the society and in every field as men were killed in that war and thousands of males had to join the military as pointed by Wharton.A (2004). Women joined the work force and they were engaged in mostly feminine types of work. This trend knew a change in the late 60's and beginning of 70's where feminists voice their opinions and were able to come forward to show their capacity and contribution in the society and they become aggressively engaged in the world of work (ILO, 1998). Through this emancipation women knew an ascend in the work force and in the society as well.

However, according to the 2009 statistics of unemployment from the CSO of Mauritius, the percentage of unemployed women is higher compared to men; 14,900 males that is $35 \%$ and 27,200 females that is $65 \%$. It can be seen that women in Mauritius still finds difficulties to get a job.

\section{Glass Ceiling}

The concept of glass ceiling has always been a subject of discussion when it comes to the gender issues in organisations. Knutson and Schmidgall (1999) looked up to this issue as an invisible and artificial barrier that prevent individuals, mainly women within the working area from attaining the higher level of the hierarchy. On the other end, a research study carried out by Marshall (1995) has shown that women tend to reject managerial roles as from their point of view this category of work was unappealing and required discomfort in performing and conforming to it. David and Woodward (1998) are also of the opinion that women themselves are reluctant to confront or break the glass ceiling as from their eyes it signifies much damage to oneself.

Based on the patriarchal discourse of their traditional roles as females and mothers, women are more likely suited and viewed as emotional workers. The organisational setting and the stereotyped perception of female workers correspond to the conventional image of the roles of women (Nicholson, 1996). Women's fostering virtues contribute towards making her more apposite to support roles (Etzioni, 1969). Forming the majority of emotional workers, women tend to be susceptible to the glass ceiling phenomenon.

\subsection{Hospitality Sector in Mauritius}

Mauritius economy is based on different pillars and the hospitality sector is the third pillar which contributes extensively in the economic progress and overall development of the island. Mauritius, the "paradise island" in the Indian Ocean is bestowed by many God gifts; sub-tropical climate, eye-catching beaches and most importantly the Mauritian hospitality. The $3 \mathrm{~s}$; sun, sea and sand have been well 
explored by Mr Amédé Maingard; the director of the hotel "Le Park" in the late 1950s and it was the first hotel in Mauritius. He was a man of vision and the MTPA supported the idea and the slogan "Mauritius c'est un plaisir" was brought into focus by the MTPA itself due to the increase in competition.

\subsection{Women's Place in the Hospitality Sector}

The tourism industry of today is also termed as a "women industry" by several writers; a very female oriented one. A bulk of research has been conducted in order to understand the chemistry behind high level of women in this particular area and it must be noted also that the tourism sector is also known as a hospitality sector and this idea explains the reason of the huge employment of women (Biswas and Casell, 1996). With the introduction of Equal Opportunity Act 2009, women are being treated equally as men in every sphere and also she is being promoted and protected by the government with new legislations. According to the CSO statistics, it has been found that the employment of women in the tourism sector has been increasing during the past two years. Even the ILO Report (1998) gives a picture of women as an economic driving strength.

Addressing the subject, Biswas and Casell (1996) pointed out that women are being viewed under several roles in the hospitality sector; caretaker roles, the charmer role, out of the ordinary roles and also the mother-earth role as the caring aspect of women have always been a luxury and through job like chambermaids in hotels, this aspect of them were being used. Moreover, they are being seen as sexual entities, objects of pleasure and the allocation of job like hostesses demonstrate how the roles of seducing people are allocated to women which somehow contributes towards a competitive edge for this sector.

\subsection{Job Categories}

Purcell.K (1996) has been one of the great researchers who have been able to unravel the mysteries behind the huge employment of women in the tourism sector. She has based her study on contingently-gendered jobs, sex-typed jobs and patriarchally prescribed jobs.

For a business to perform well the employer would want high profit maximisation at any cost and the contingently gendered jobs is based on the fact that no matter who is performing the task, having cheap labour to perform it will be better from the eyes of the employers. Marxists' opinions were that women are "victims of capitalism which attempts to control the labour processes by keeping wages and cost low". According to Hochschild (1983), seems the paid and unpaid work which demands the use of emotions in order to ease the work flow either in or outside the organisation. Taking into account that the hospitality sector is a sector which requires much exposure of the display emotions and the self, Gabriel (1988) advocated on the fact that female workers are more prone and available for these jobs as they are not the 
main source of income in a family and therefore they work for low wage and on a part time basis.

Coming to the sex typed jobs, it can be debated that women who form part of the hospitality sector are being objectified as a sexual object. For instance hostesses, waitresses are supposed to be attractive with a smile, well shaped, and with special types of attire which can give their body as well as their personality of that of a charmer. Purcell.K (1996) noted that in the hospitality sector an employee's personality tend to be a representative of sexual attractiveness and much more important than the qualification. Hochschild (1983) in her studies of the flight attendants showed how the smile of a lady attendant can be sexualised and the female attendants need to respond to the "sexual fantasies" of the customers. This shows how the appearance of women must appeal to the market requirements and also the employees must "think sales" (Hochschild, 1983); more clearly the sales of the selves in order to increase the competitive advantage of the company. Biswas and Casell (1996) found how female workers were being use as a marketing strategy to attract male customers for organisational profit maximisation.

The last but not the least, the patriarchally prescribed jobs takes into account the idea that women has always been dependent on men and therefore when they perform for low wage and part time jobs showed women as a complement of men; not on equality basis as it has been noted by Bell and Newby (1976).

\subsection{Emotions Used as a Means to an End}

\section{Emotions at Work}

Emotion management is a common practice in many types of occupation and it is principally put in to practice on workers who interact highly with customers as a part of their service work (Hochschild, 1983; Rafaeli and Sutton, 1987). Ashforth and Humphrey(1995) further argued that organisations promote at least 4 methods to regulate emotions both formally or informally to be precise, neutralisation acts as a regulator for unwanted emotions, secondly buffering encourages the partition of emotions in such a way so as it does not clash with the ongoing work, thirdly prescription which emphasises how to stipulate felt and displayed emotions and lastly normalisation where one must be in line with the organisational culture in a consistent mode. Emotion at work is being used by employers as a manipulative tool in order to better control and exploit employees which gives rise to emotional labour.

\section{Emotions and Capitalism}

The human asset in any organisation determines its height on the economic ladder of success. The capitalists together with the alliance of HR managers usually find means and ways of getting the best out of their employees; exploiting them to the maximum. From the eyes of the capitalists, emotion is being viewed as a commodity which must be exchanged as a value in order to achieve success. The performance of emotional labour is a value dispersing, a product which is heavily commercialised in 
order for profit maximisation and competitive advantage. Hochschild (1983) even goes to the extent to demonstrate that emotional labour "absorbs the worker" in the working environment and into emotional entities which they exhibit in front of customers for surplus value. Therefore under the capitalists' system, humans are becoming objects and their very souls are open to management interrogation. Women being the weaker vessels and the most disadvantaged workers have been the victim of this conspiracy of the capitalists. They have been marginalized and dehumanized in the whole process. In addition, training programs are being offered as a management tool for better manipulation and regulation of both outer and their private inner selves. This expresses to what level the capitalists make use of managerial practices for maximising profits, no matter of its consequences.

\subsection{Emotions and Control}

\section{The Panopticon}

"The body is involved in a political field where power relations have an immediate hold upon it, they invest in it, train it, torture it, force it to carry out task, to perform ceremonies to emit science" as articulated by Foucault (1977). This demonstrates to what extent there is no dignity to the human body. By the full fledged diagnosis of Foucault (1977), it can be claimed that discipline creates "docile bodies", and as a result these 'docile bodies' must be constantly observe and record their actions and also ensure the internalisation of the disciplinary individuality within the bodies being controlled. The panopticon was the ultimate realisation of the modern disciplinary institution where constant observation characterised by an "unequal gate"; the constant possibility of observation (Foucault, 1977). It is a "captive" state of conscious with an unending visibility which leads to the total management of power in order the surveillance mechanism works in such a way so that the flawlessness of power if it is irregular in its conduct, it should be able to make this architectural tool as a mechanism for the creation and maintenance of a power relation irrespective of whoever is exercising it and Foucault writes: "He who is subjected to a visibility, and who knows it, assumes responsibility for the constraints of power.....he becomes the principle of his own subjection" ( Foucault,1991).

Management nowadays has been given the job of luring employees into loving the company, its products and customers. Organisational actors' emotions are being captured and damaged in the velvet cage of corporate culturism. Rose (1991) explains how the way power functions and going to the extent of 'shaping the private self', where the individuals are subjected to knowledge and discourses in order to construct their very identities and it can be said that the private sphere of the humans is in the grip of the capitalists where Your self is not yourself; your own identity is taken out of yourself. The panopticon is therefore a means for employers to gaze on his employees and "trusting" them at the same time. This brings to another standstill where there exist the great disparity between the "seeable" and the "sayable". 


\subsection{Emotions and its Human Impacts}

\section{Alienation and Exploitation}

Hochschild (1983) was very concerned of how emotional workers were being alienated from their true identities. She also pointed out the negative outcomes for workers, specifically: burnouts, job dissatisfaction, and feeling of inauthenticity. This brings into light the idea of alienation from labour and its products. The workers become alienated from their very own emotions as it is being commercialised. Hochschild (1983) showed the conflict that arises between real and displayed emotions; "Freeze your smile", "Natural niceness". Emotion work is no longer a private act but rather a public act. She illustrates how under capitalism there do exists the fusion between felt and displayed emotions which clearly shows how these workers are puppets in the hands of the capitalists as they are unable to manage their own feelings.

\section{Emotional Dissonance and Emotional Exhaustion}

Emotional dissonance arises when one complies its emotions with the organisational rules and at the same time being in conflicts with its own emotions (Rafaeli and Sutton, 1987). These writers explain how under scripted form of work these conflicts take place and emotional dissonance is an internal conflict. These emotional dissonances can have psychological impact on workers such as depression. Hochschild (1983) demonstrates how "social exchange is forced into narrow channels" and also "there is much less room for individual navigation of the emotion waters", which showed how the workers have few avenues to express their innermost feelings and result as both emotional dissonance and exhaustion. These workers are being treated as 'mindless machines' and if they showed resistance to work they are being ordered to "go into robot" (Hochschild, 1983) and these workers have to comply with their own feelings and some even perform this emotional work by using and selling their very own feelings for wage will contribute enormously towards emotional exhaustion.

Sexuality is part of the oppression and conformity of women within the world of work. For instance, waitresses are supposed to perform "open sexual bantering". The tourism sector takes for granted the stereotypical nature of women. Personalities such as always smiling, friendliness, their bodies, and emotions are being sold in the service factory. For example, the brochure of any hotel, the nakedness of women is being exposed as a means to attract customers. Today the spa facilities in the tourism sector are becoming a must and as far as we see it has always been the women who are being allocated these types of tasks. These emotional work performed by these women will surely contributes towards breaking their character due to conflict with their own feelings. 


\section{Psychological and Health Consequences of Work}

Conceptualized and operationalised by various scholars, emotional labour being paradoxical in nature can lead to psychological distress due to the conflict between felt and displayed emotions (Hochschild, 1983; Erickson \&Wharton, 1997; Persaud, 2004). Compared to men, women tend to have vague symptoms like headaches, fatigue, discomforts, minor depression and chronic pain which are unable to correctly identify as they are not well defined (Oakley, 1994). Having to manage emotions in several ways can lead to work stress, job-related depression, psychosomatic complaints (Mann, 2004). He further emphasized on heart disease, exacerbate cancer, emotional burnout and the strain of masking those emotions. There have been many researches carried out to show the dilemmas related to emotional tasks namely a scientific report which shows the link between anger and heart disease (Appel et al., 1983).

\section{Dignity at Work}

By making female employees performing emotional labour under the manipulation of the capitalists, we will find that this balance of emotions required by those employees to avoid coldness so as to respect the clients and this form of emotional labour can give rise to disrespect and undignified when it comes to the worker's point of view(Sayer, 2007) . Performing emotional tasks, for instance, compulsory niceness under pressure and lack of trust erodes dignity and also can be viewed as undignified for both worker and customer. It can also contribute towards distancing the worker from his or her work. Dignity and respect are very crucial for workers for them to perform their work duly and to be emotionally attached to their work.

\section{Conflict at Work}

Ackroyd and Thompson(1999) in their book Organisational Misbehaviour tries to attempt the issue of the neglect of employees and also the notion wayward workers together with fierce criticisms of the organisational change which brought employees to such dilemmas. They use the term "misbehaviour" in order to show many forms of resistance from the workers side and the wide spread in the organisations. Various researches have shown how these employees are being trained so as these workers fit the organisational grid and these rules are imposed on them. Hochschild (1983) in her studies of these flight attendants she showed how organisational display rules are being imposed on them. Van Maanen and Kunda (1989) have given clear examples how workers misbehave while facing rude customers and as a result they over-tight their seat belts and making them feel uncomfortable. Definitely workers will be frustrated as their emotions are being commercialised just for the sake of profit maximisation of the organisation.

\section{Work-Life Balance}


This change in the working lifestyle has contributed a lot towards women getting the proper equilibrium between their private and professional life. Researchers have shown that despite of their marital status and salary, women at the end have complied to do their traditional household chores together with the work life contrary to men. Hochschild (1989) pointed out that women of today are allocated with two jobs; office and at home.

\subsection{Conclusion}

Concluded from the above research study it can be said that the true facet of emotional work of women has been untied to a very large extent and bringing forward the whole masquerade of the capitalist society. It has also painted the place occupied by women in the service sectors and together with all the atrocities and the reality of the world of work that they are subjected to. This brings this study to another extreme as whether women will continue to face these dilemmas at work, that is to continue selling their emotions or there is still a light of hope at the end of the tunnel.

\section{Representation and analysis of data}

\subsection{Introduction}

This chapter embodies the representation and analysis of the gathered data through questionnaires. This process has been carried out in order to give a proper dimension of the information via graphical presentation and thus easing the flow for the conclusive part. The response from the hotel was very motivating and after compiling all the questionnaires, 100 questionnaires were taken into consideration so as to limit matters of biasness.

\subsection{The Gender Distribution of the Service Work}

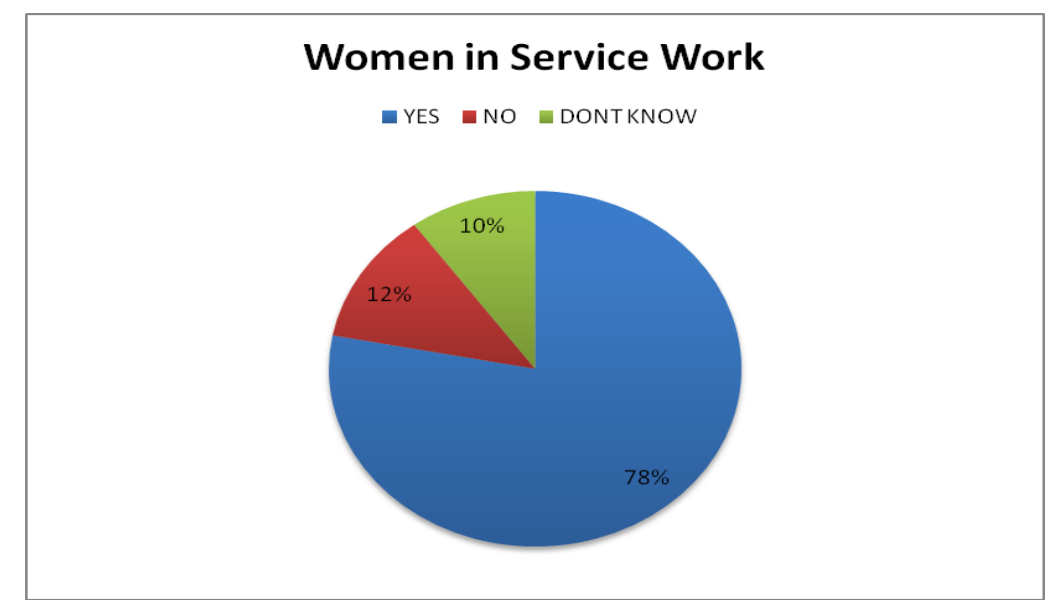

Figure 3.1

From the above chart, it can be noticed that $78 \%$ which constitute of the majority agreed that it is the female workforce who mostly occupy the service work. This figure gives justice to the research conducted by Biswas and Casell (1996) as 
they portrayed women as those who are more prone to emotional work under roles like the charmer, mother-earth and caretaker amongst others. From the personal interview conducted, even the manager herself viewed the workforce at hotel and the hospitality sector as a "female care-oriented" one.

However, from the internal records of the hotel, the gender distribution of the working population of women was $28 \%$, which justifies the CSO report (2009) which showed $65 \%$ of women are unemployed. This also contradicts what was stipulated by several authors as they put forward that the hospitality industry is a "women industry". Reports from the ILO (1998) and the CSO statistics in the past two years specified the increase of women in the work force especially in the tourism industry; nevertheless the figure of the representation of women at the hotel opposes this view.

Moreover, $12 \%$ of the interviewed population disagreed with this statement as they were of opinion that even males are able to perform those services work at their best. From the survey session, it can be concluded that in fact men do exhibit emotional advances as the organisation's motto towards customer excellence guide their instincts to job promotion. Additionally, gender competition is at the very basis of every successful organisation irrespective. Therefore, the $12 \%$ population section does provide for a new justification to the opposition authors who view the tourist sector as female dominated one.

\subsection{Emotional Labour and its Duration}

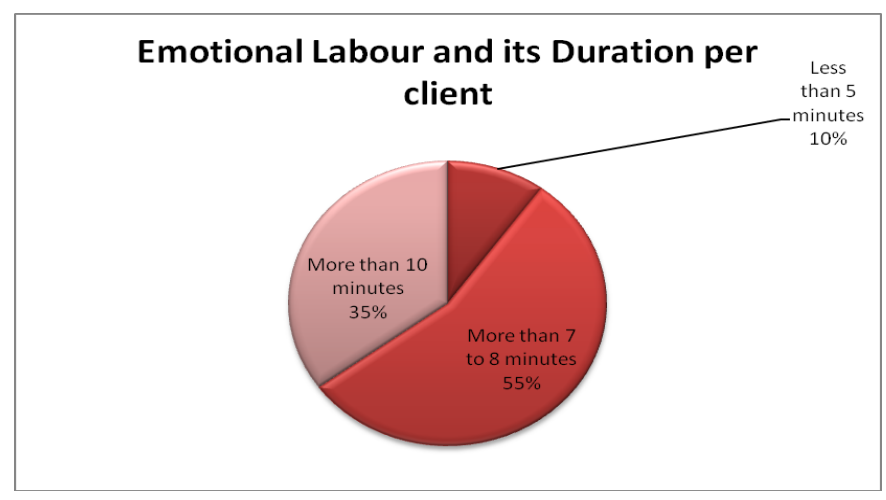

Figure 3.2

It can be seen that $55 \%$ was reported on the time interaction of more than 7 to 8 minutes with the customers and $35 \%$ on more than 10 minutes. This figure shows that during the interaction these employees need to control their very own emotions and as well as the management of the customers' emotions which confirms the argument of James $(1884,1950,1994)$ and Hochschild (1983). These employees need to comply and shape their behaviour according to the display rules prescribed by the hotel as Wharton and Erickson (1993) conceptualized in the literature as "employers' efforts to shape workers' emotions and emotional displays". This interaction also highlights the intensity of exploitation and conflict that the employees bear between displayed and inner emotions and it is mainly the women front liners who have to deal with these situations as they are the one who highly interact with customers. 


\subsection{Women and "Service with a Smile"}

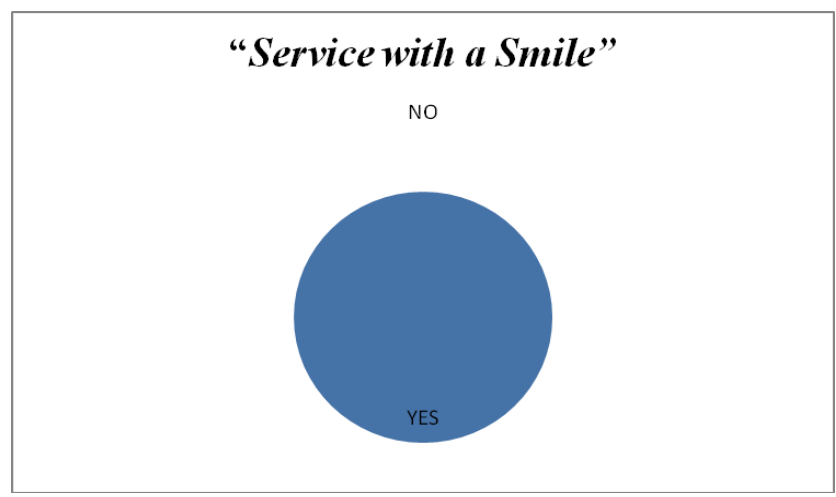

Figure 3.3

From this diagram it can be depicted the idea that "Service with a smile" is a prerequisite form of emotional labour which needs to be put forward for a better customer's service. Emotional work like "Freeze your smile" or "natural niceness" mentioned by Hochschild (1983) can be found in action in this service role. This $100 \%$ of response also shows to what extent women should manipulate their very own feelings so as to produce positive energies vis a vis their clients. Some even pointed out that "Smiling is part my work" which demonstrate that these ladies are being mould in such a way that they should automatically smile to the customers in order to fit the grid that the capitalists together with the human resource manager constructed for them and indeed the information gathered from the personal interview reported that the manager makes it a must to ensure that the employees are practising emotional labour through the "Service with a smile" with on site monitoring of job performance by the middle management.

\subsection{Emotional Labour and Prescribed Rules}

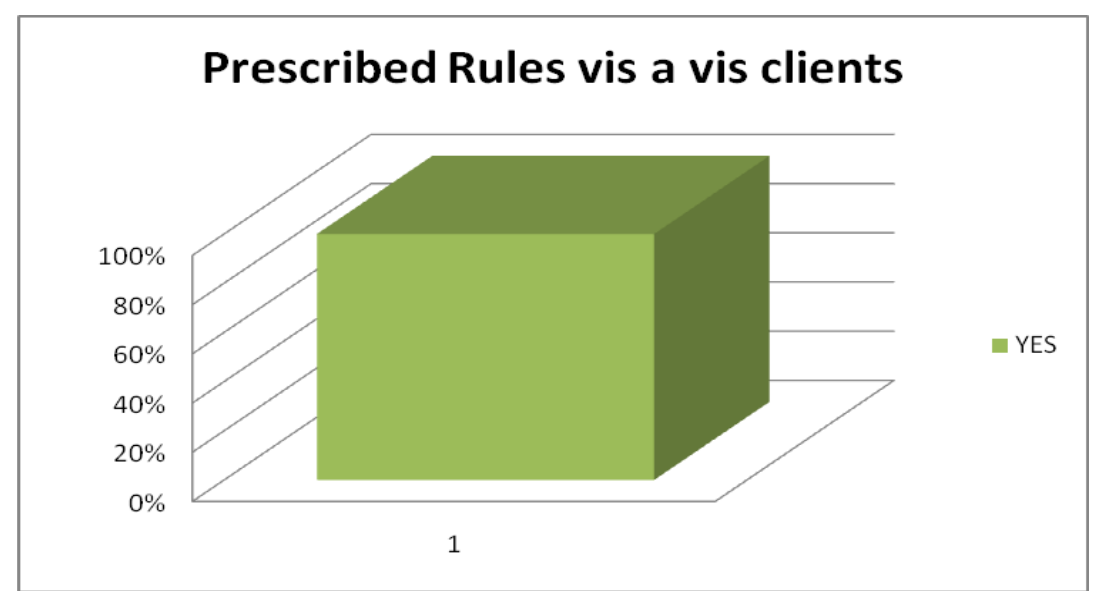

Figure 3.4 
This graphical representation was very interesting to analyse as there was not a single negative answer which shows the level of control that the management exerted on its employees which gives justice to the Foucauldian concept of panopticon. The management makes it a must to inculcate the idea of "Customers should be treated like king" as nearly three quarter of the answer given as examples to this question the respondents quoted that phrase. It also shows the level to which the employees have made this value a part of their daily activities. It also validates the idea of display rules which has been demonstrated by Rafaeli \& Sutton (1987). The above also confirms the view of Pugh (2002) as the female employees tend to stick more to these display rules as they tend to suppress more of their inner feelings. By the creation of a Centre for Excellence in the hotel, the management guarantees all interaction must be done under prescribed rules as the human resource manager articulated in the personal interview and this managerial tool helps for better control of the tasks of the workers.

\subsection{Deep and Surface Acting performed by Female Workers}

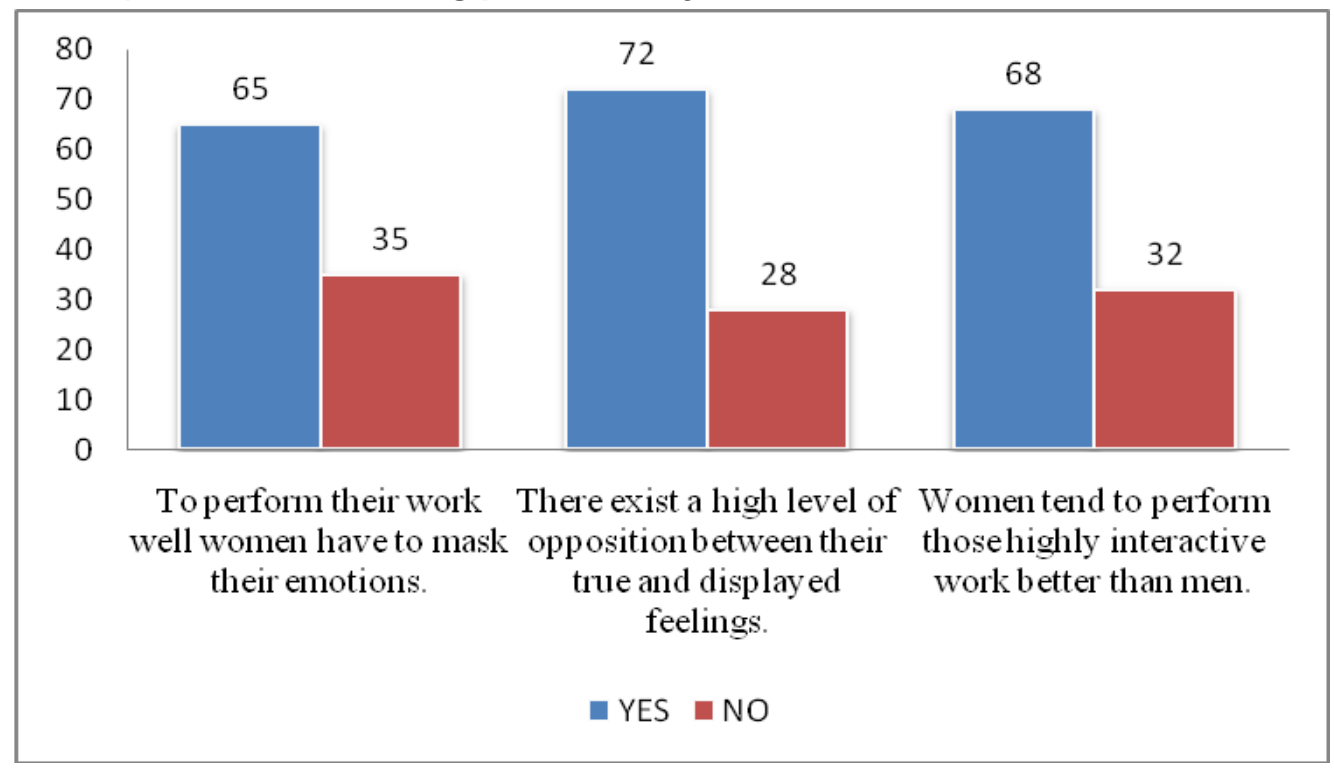

Figure 3.5

The diagram above illustrates the degree to which women should engage themselves in deep and surface acting. Here we see how ladies are prone to these types of acting so as to perform duly their required work. The percentages also demonstrate the remarkable distinction and conflict between felt and displayed emotions which authenticate the research of Mann (2007). This figure also validates the view of Isenbarger and Zemylas (2006) as to perform emotional labour there need to be control between what is felt and what it is displayed. The chart also portrays the profound manipulation of their very own private spheres in order to deliver their goods which correlates to the finding of Rose (1991); 'shaping the private self'. 
Emotion is being viewed as a priceless source of revenue which the capitalists have been able to recognise and market that. This display depicts how the capitalists have to get in the inner selves of its employees in order to retrieve the maximum from them. 68 respondents agreed that women tend to perform interactive work better than men and this situation can be said to be the result of the setting of the organisation and their premade and long-established roles which has accounted for female workers to be viewed as better emotional employees as validated by Nicholson (1996).

On the other side, there does exist a small minority who do not agree on the above statements which shows that even men are able to perform those emotional works which confirms the research of Gross and John (2003), who elaborated that even males tend to engage more in service acting. From the $\mathrm{PI}$ also, the human resource manager puts light that there does not exist any sort of "biasness" when it comes to orientation of emotional work.

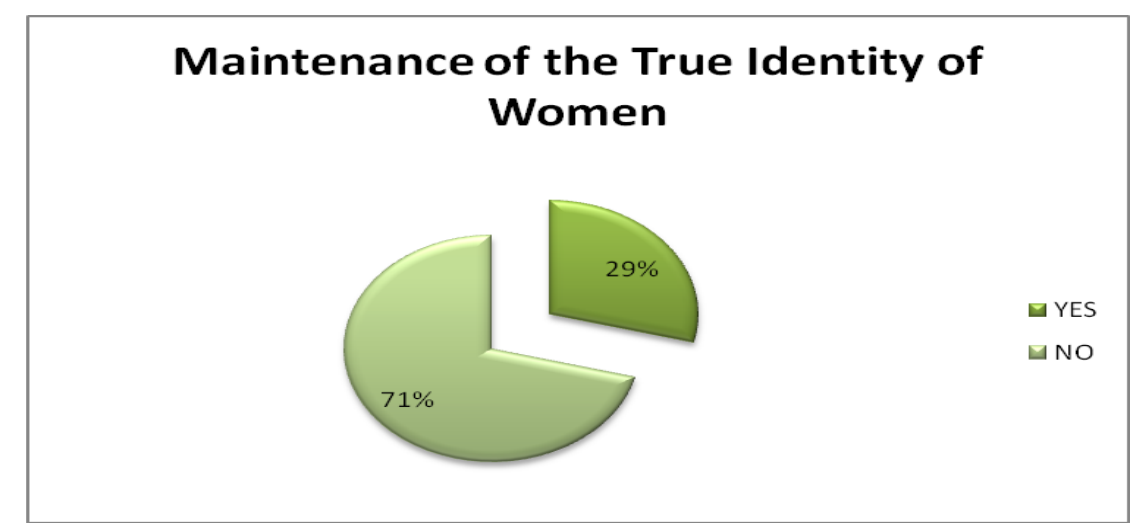

Figure 3.6

The aim of this question was to further analyse how deep and surface acting is performed when they are in full encounter with the customers. Through the analysis of the question it was found that women have to produce those emotions which are required by them by the organisation which validates the view of Morris and Feldman (1996) who believe that it is "the act of expressing organizationally desired emotions during service transactions" and that of Ashforth and Humphrey (1993) who articulated that it is "the display of expected emotions". These women need to abide by the rules set by the management. They are not able to express what and how they feel in real situations. Sentences like "Women cannot express their frustration to the customers", "Women have to accept customers' misbehaviour or bold comments and stay quiet" were recorded. These phrases show to a very large extent the compliance of the emotions those women while performing their work; either "faking in good faith" or "faking in bad faith" as authenticated by Rafaeli and Sutton (1987). This question also portrays that the organisation makes it an obligation for its service actresses to abide to the display rules set by them and engage themselves in intense deep or surface act. It was very contradictory from the information gathered from the personal interview, as the manager pointed out that the top level management assure that employees 
perform work that they like and also that their emotions are real. Here, we can easily see how there is a contradiction between the perception of the management on its employees and the real situation prevailing at the hotel which shows the disparity between the "sayable" and the "seeable". In addition, the findings of Ashforth and Tomiuk (2000) contradicts the belief of the human resource manager as according to them even if employees are in a position to recognize themselves with their work, they will not be always able to perform on management expectations.

\subsection{Emotions of Women at Work}

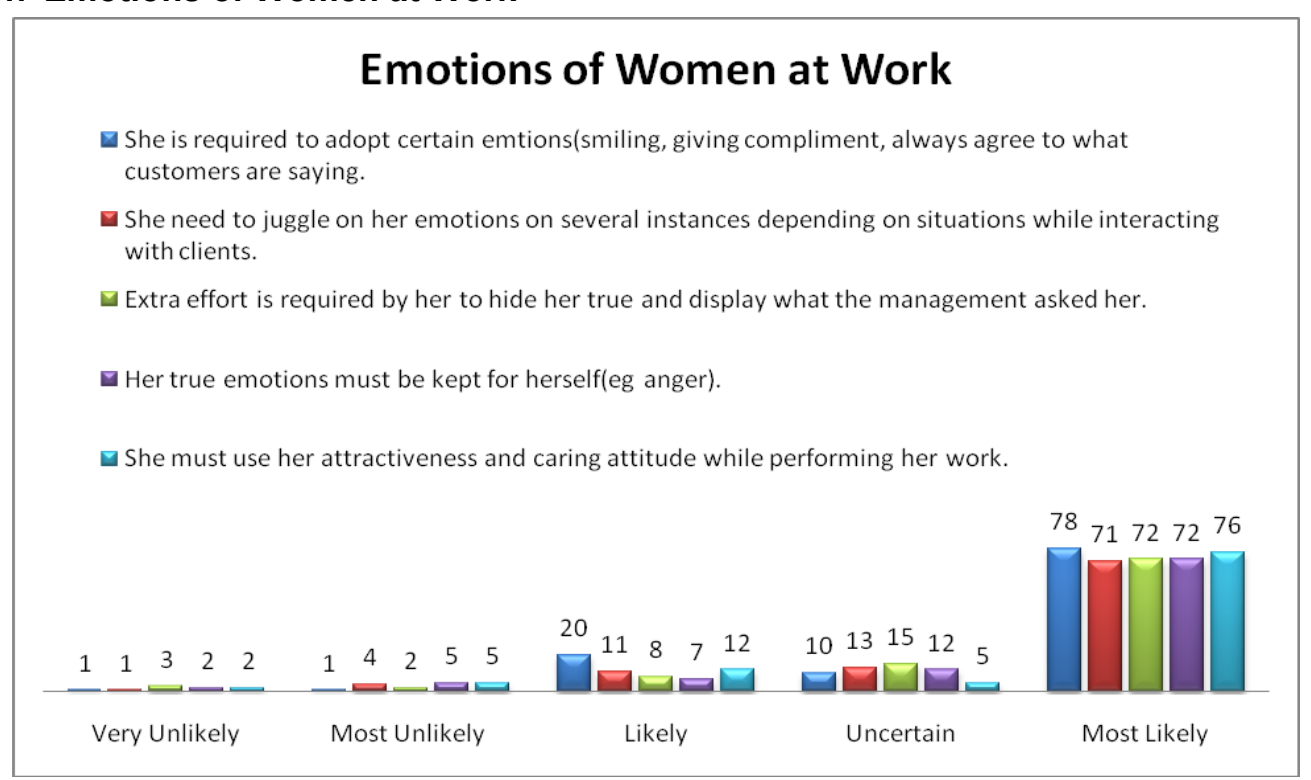

Figure 3.6

These statements above were designed in such a way so as to find the relationship between the emotional works that women perform under the manipulation of the management together using sensuous image for better "delivery of the goods". The first four statements put on view the 4 methods of emotion management presented by Ashforth and Humphrey (1995); neutralisation, buffering, prescription and normalisation. The percentages related to these four statements are all greater than $\mathbf{7 0 \%}$ on the scale of most likely which exemplifies how the management of emotions are being carried out under strong regulation of the private spheres of these women and making them mindless machines through the mortification of their very own identities. Faking their emotions and being engaged in deep acting towards clients, these women besides deceiving themselves they are deceiving the customers as well. The internalisation of the feelings of the women makes them isolate from their real emotions. It can be deduced from these percentages that out of these phase of commercialising the emotions of women, the latter must use certain qualitative emotions according to customer requirements as mentioned on the above chart.

In addition to this, the last statement indeed portrays the idea of women being viewed and objectified as an attractive entity in the service industry in the same way as 
Hochschild (1983) sees women as "sexual fantasies" and Purcell (1996) as well. Moreover, it also correlates to the research of Biswas and Casell (1996) who view women as a marketing tool, a sexual centrepiece that the capitalists promote for further maximisation of profit. Women are also being exploited for their caring attitude that they possess as mothers. Extracted information from the personal interview, the manager acknowledges the importance of looking and being attractive as it is a customer oriented sector and therefore women being attractive will contribute towards the good impression on the hotel and this response from the manager confirmed what Hochschild (1983) stated when the latter put forward that employees must "think sales".

Thus one can draw the conclusion that women are not only being exploited as emotional workers but even much more than that. Both her emotions and body are being put to the commercialisation process.

\subsection{Stereotyping Women's Work}

This question was put forward so as to inspect whether there was the presence of gender stereotyping at the hotel.

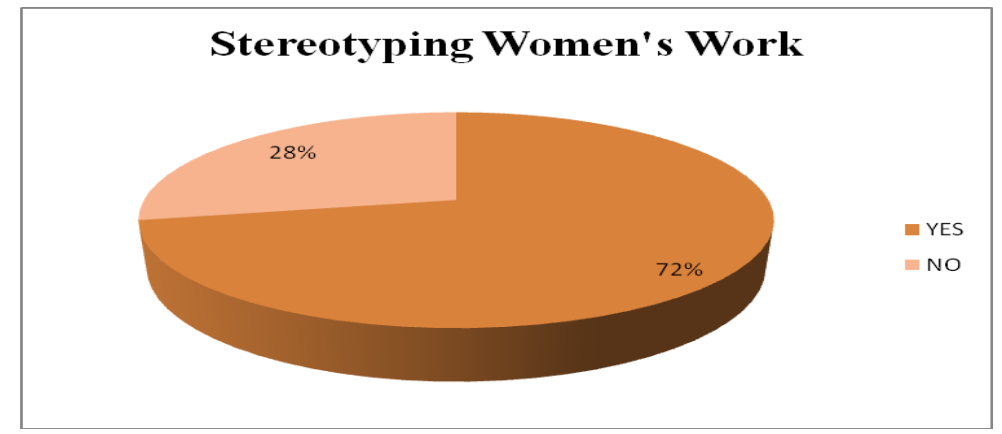

Figure 3.7

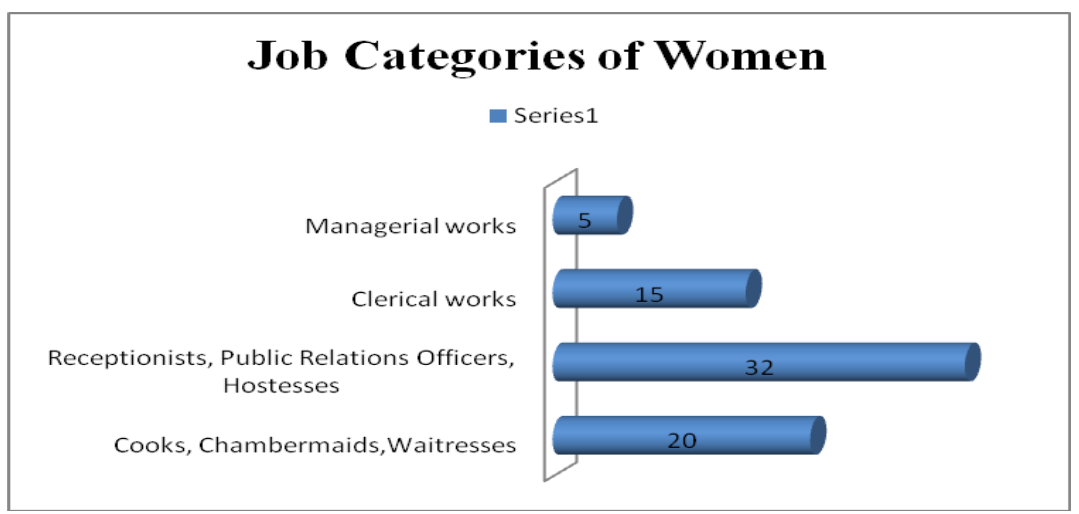

Figure 3.8

On 72 people replying on this issue, 32 agreed that women are best as receptionists, public officers and hostesses as according to them it is more pleasant to 
talk to a lady on the phone or deal with them in any circumstances due to their level of understanding and caring attitude. Some even pointed out that ladies are more attractive and putting them in strategic places like the reception or to perform as hostesses will give justice to both their beauty and the clients' expectation which confirms the argument of Purcell (1996) who noted that personality is linked with sexual attractiveness. 20 people approved on women are mostly suited as cooks, chambermaids and waitresses as to their view point, women due to their unique human touch and homely outlook these roles are more apposite to them. This response correlates to the expected role of women presented by Biswas and Casell (1996) and the job categories argued by Purcell (1996). These studies confirmed the fact that indeed women tend to perform task like mother earth role; chambermaids, waitresses. Here we can figure out that organisations are duplication of the society, that is, the roles that women perform at home are similar to what they carry out in the world of work which confirms the idea of UNIVERSAL DIVISION OF LABOUR by Friedl. E( 1975). In addition to that, they are also being used as a charmer; jobs like waitresses, hostesses and they are being viewed as an attractive object which must be presented to the customers of gain in competitive advantage and also exploiting them to the utmost.

Very few respondents gave their agreement to the category of women taking managerial tasks and this can be of the presence of the glass ceiling phenomenon.

\subsection{The Glass Ceiling and the Representation of Women at the Top Level}

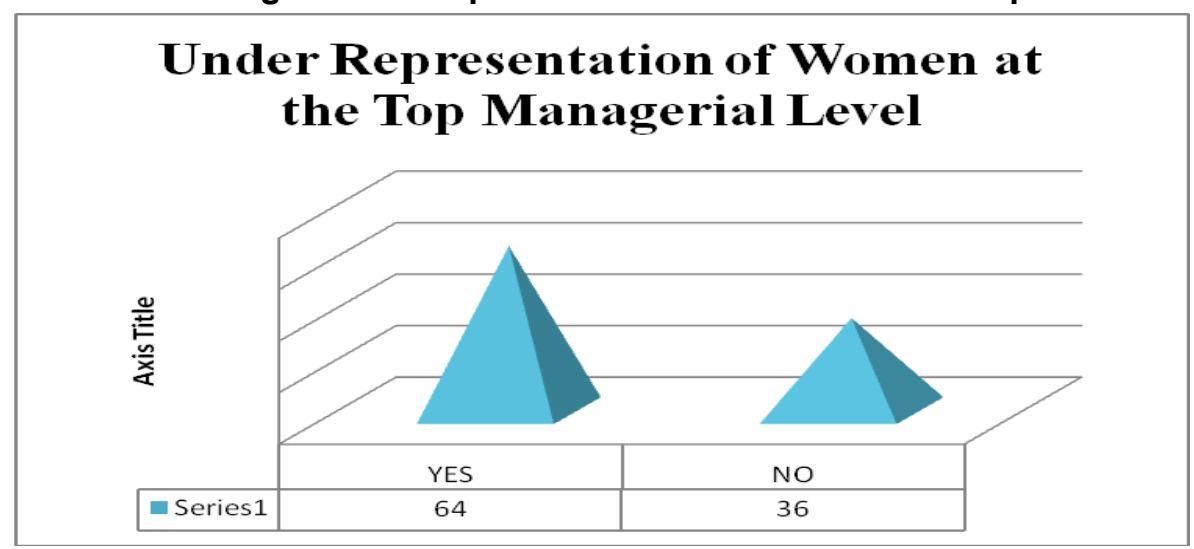

Figure 3.9

From this survey it can be seen that $64 \%$ of the employees reacted genuinely to this issue. This under representation of women at the hotel showed the even now women find it difficult to smash the glass ceiling phenomenon. Through the figure above, it is clearly understood that women are still victims of the "glass ceiling" and the patriarchal nature of the society which confirms the view of Nicholson (1996). Their feminine nature and tenderness portrays them as the weaker vessels and contribute towards making them more apt as emotional workers which asserts the opinion of Etzioni (1969) and placing them down in the organisational hierarchy and the response from the personal interview also shows that women are being placed down in the 
hierarchy but very intelligently the human resource manager showed that it is the lower level management who contribute towards the success of the organisation.

On the other side of the coin, on a deeper analysis from those who replied "No" to this answer provide justification like "Women themselves are not willing to take up responsible position". This remarkably justify the study carried out by Marshall (1995) and David and Woodward (1998) who were of belief that women do not show enough of enthusiasm to take up managerial work.

\subsection{Women and Part time jobs}

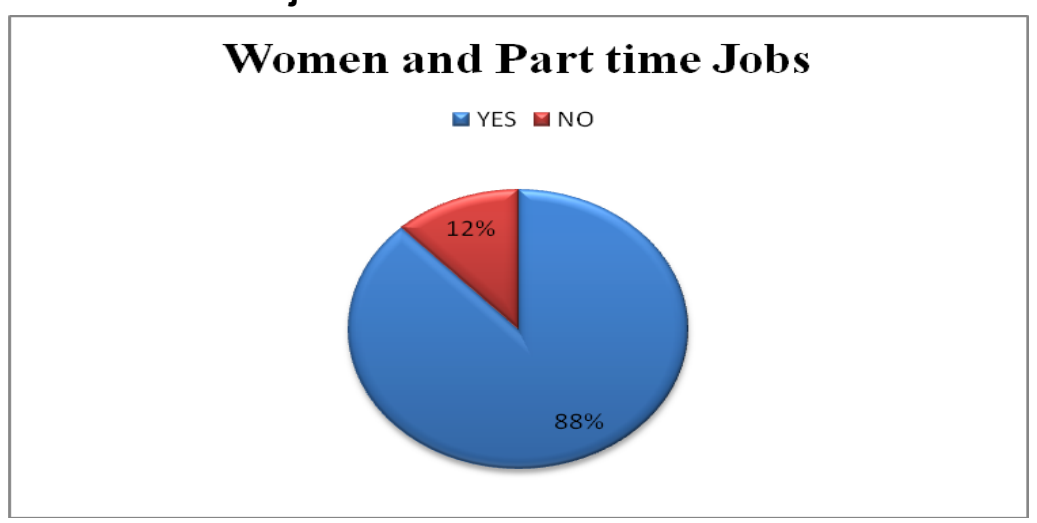

Figure 3.10

This question was being put forward so as to analyse whether women mostly take up part time jobs or not. The above validates the observation of Marx that women are viewed as a resource which the capitalists need to exploit for profit maximisation as women are low wage worker. An overwhelming majority of $88 \%$ agreed on the fact that because of family pressures, women take up part time work, which illustrates that the working life of women takes the second position and they are more available for low pay and part time jobs which correlates to the finding of Gabriel (1988).

\subsection{Women and Exploitation}

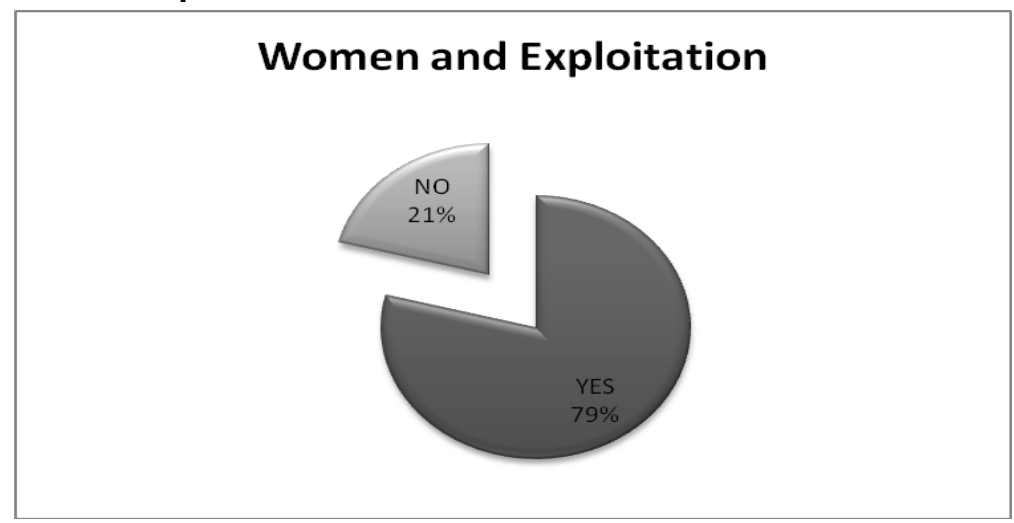

Figure 3.11 
A large majority of the population acknowledged the idea that the female workers are undeniably more exploited compared to men as women are only viewed as a substitute of men which coincide with the argument of Bell and Newby (1976). The justification given to this answer by the respondents was that women do not show much resistance as male employees do. They accept work load imposed on them. As they are not represented at the top level management, it becomes easier for the capitalists to better manipulate these women. It can be concluded from the above that even in the modern society that we are living, women are still being dehumanised and marginalised.

\subsection{Realities of the Working Conditions of Women under the Capitalists Regime}

\section{Women and their Working Conditions}

$\square$ Women are given the chance to voice their opinion in any decision taken concerning their work.

I The work allocated to them is highly scripted and firmly controlled.

- The job gives them the opportunity to take initiatives and do whatever deem is right according to them.

- The work gives her significant independence and freedom in how it should be carried out.

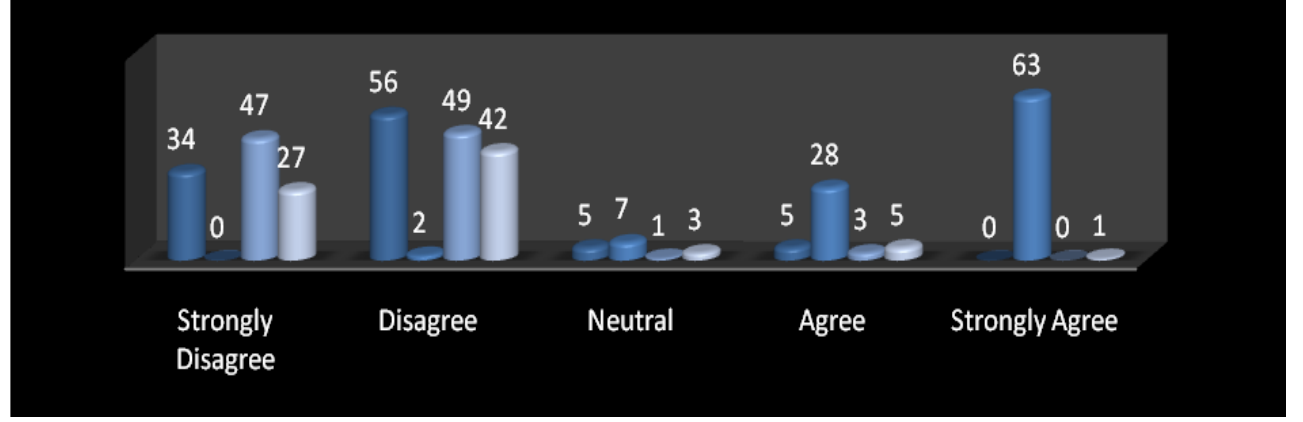

Figure 3.12

These series of statements will help to evaluate the degree of independence that women get for them to perform emotional tasks and also the autocracy exhibited by the capitalists upon its employees in order to make them "docile bodies" as mentioned by M.Foucault (1977). From the percentages above, the real working life of women under the capitalists' society has been unknotted to a large degree. Women carry no autonomy in the work they perform. They are neither able to voice their opinion nor to take initiatives to perform their jobs. The figure above gives rise to an alarming issue as these women do not wish to be treated as machines that can be fitted in any place which confirms the view of Hochschild (1983) when employees are commanded to "go into robot". This demonstrates to what degree women have been victims of the exploitative nature of the capitalists. As women are segmented within the organisation, it becomes easy for the capitalists to better control them through Tayloristic form of work; highly scripted. 
There is high level use of technological weapons like cameras that has been noted through observation at the hotel which explains the idea of the panopticon in practice which confirms the statement of Foucault (1991) "He who is subjected to a visibility, and who knows it, assumes responsibility for the constraints of power.....he becomes the principle of his own subjection". The cameras act as a managerial tool used by the top level management in order to assure that the employees are carrying out their work as prescribed, that is making employees both the star and the victim of this show subjectifying them to their natural irrationality. This clearly illustrates the degree of control that the upper level management exerts upon the lower level. Women are being dehumanised, act like puppets in the grip of capitalism and always under their constant gaze which further validates Foucault's (1991) research. The realities of the world of work are really crude from the response acquired by the employees. An authoritative management style is being depicted as there is deep internal and external regulation of the employees both work and emotions. It can be concluded from the above that the employees do not even recognize their very own identities with their respective jobs which confirms Hochschild (1983) views on alienation of employees from their work. It can be noted that there is no dignity when it comes to performing their work from the eyes of the employees as Sayer (2007) puts it as being constantly watched and bearing no trust from the capitalists will add to lack of respect and no commitment to their work. It can be said that the female employees are working only for the sake of working and not for the sake of performing.

Conversely, the personal interview does not relate to what the workers have put forward, as from the view point of the human resource manager, female employees are given the chance to voice their opinion but also she accepted the fact that the employees must follow the company policies and also what is taught to them in the training session. Here, we can clearly see the mixture between "care" and "control" exerted on the workers by the management.

\subsection{Training as a Means to Shape and Control Employees}

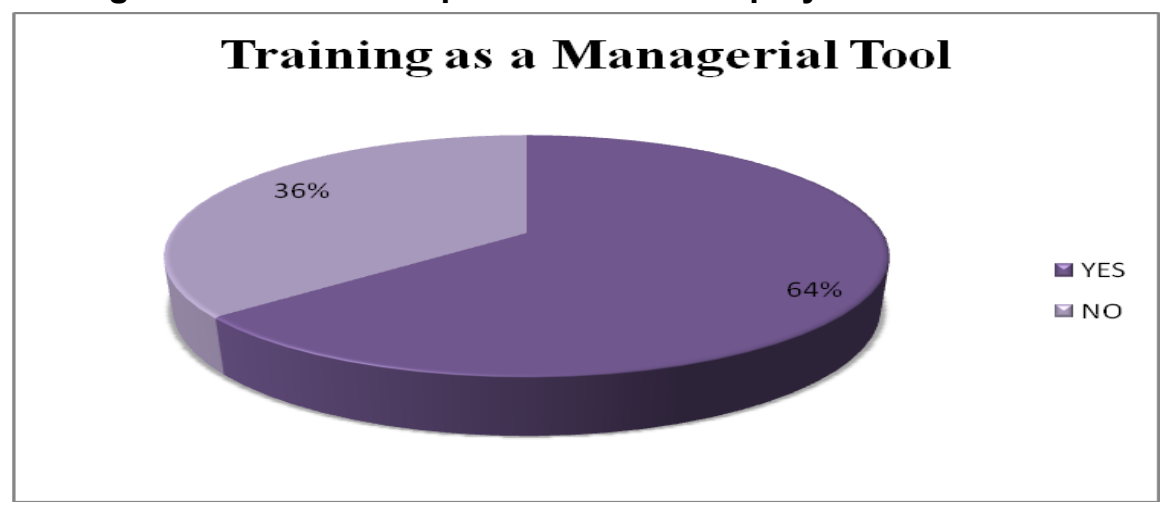

Figure 3.13

This question was set so as to have a deep insight on the hotel's training activities. $64 \%$ agreed to the fact that women do receive training for better performance of their work. It was interesting to take into account that these female workers were not 
only given training for customer interaction purposes but also how their work need to be performed as chamber maids and maintenance people. The majority of works which are subjected to female employees were trained. They were taught how a bed should be made, how to clean the room, how bathroom and toilet should be cleaned. Additionally, hospitality customer service where these ladies were taught of how to maintain a smile, courteousness, to treat customers like kings, to delight customers through exceptional service and also the idea of self control their negative emotions. They were also taught how to have a good sense of grooming which symbolises the fact that women need to put their physical attributes on display for organisational benefit. This show the level that organisation in order to achieve competitive advantage and to exploit women to the maximum make these ladies undertake trainings with the only aim of profit maximisation.

\subsection{Emotional Labour and its Impact on Female Employees}

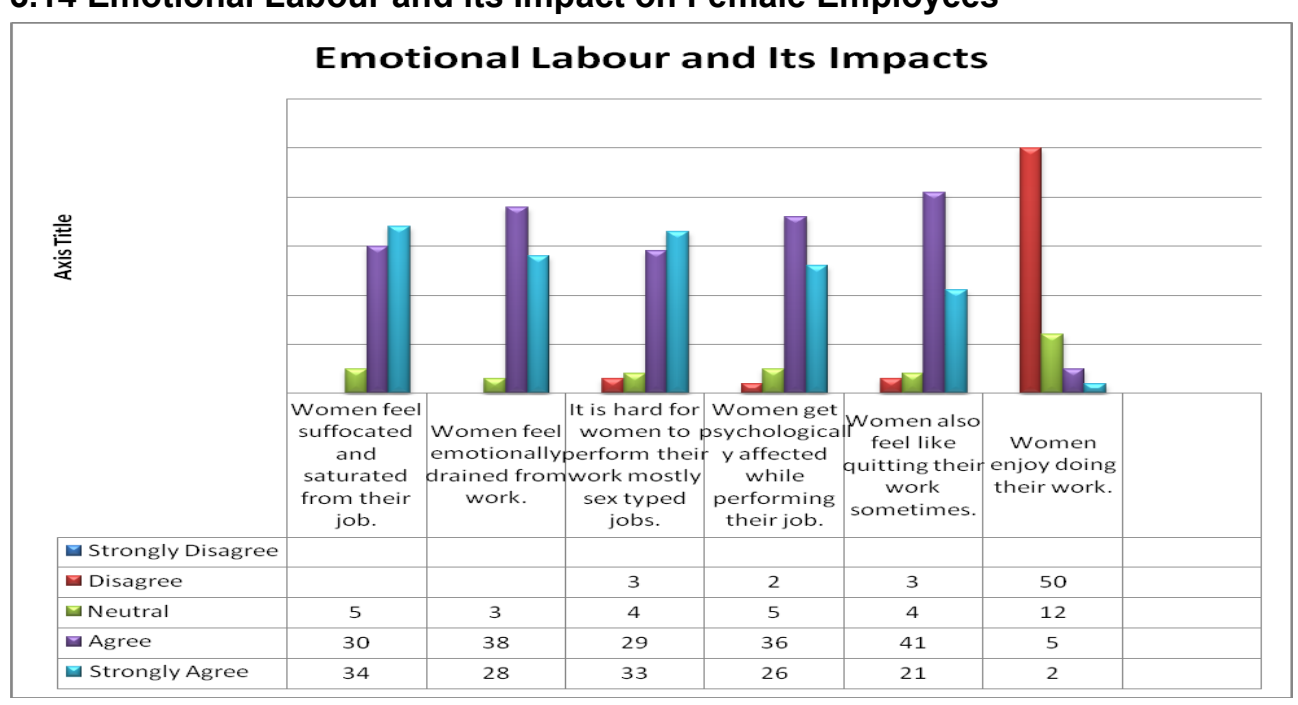

Figure 3.14

The purpose of this question was to examine the problems of emotional dissonance, emotional exhaustion and alienation. It was fascinating to see the honesty of those employees while answering this question. Out of 69 people responding on this critical issue, the majority of them strongly agreed that indeed women feel saturated from their job, being emotionally drained and that women are somehow engage in sex typed jobs. Being under the constant gaze of the capitalists and performing emotional work; being continuously involved in deep and surface act will obviously give rise to emotional dissonance and exhaustion. We will observe that these female employees do not feel any sort of attachment towards their work and customers as well. Through the process of emotional labour, they are being subject of depersonalisation and objectification. Their identities are being taken out of themselves (Hochschild, 1983) and this situation will contribute to alienation and there will not be any sense of belongingness. In addition, women are victims of "open sexual bantering". This exchange system contributes to sexual oppression and therefore 
decomposition of their very own identities where "there is much less room for individual navigation of the emotion waters" as noted by Hochschild (1983). Furthermore, 50 respondents disagreed that women enjoy doing their work. It can be deduced from this figure that women though they are caretakers, mother-earth, attractive beings but at the end of the day they do not enjoy doing these work and putting themselves to the commercialisation practice. The above figure also contradicts what Wharton (1996) accentuated on women as employees who like performing emotional work and also what Conrad and Witte (1994) stated on their notion of emotion management as being fruitful for the employees to handle their hazards of performing emotional work.

\section{Emotional Labour and Psychological Dilemma}

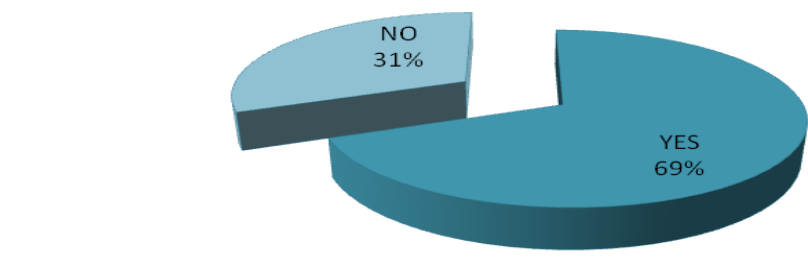

Figure 3.15

The figure above correlates to the argument brought forward by various researchers namely Hochschild (1983), Erickson \&Wharton (1997), Persaud (2004) and Maan (2004) concerning the psychological dilemmas and job related dejection. A lot of respondents mentioned "stress", "hypertension", "monotony" and under the research of Oakley (1994) showed that the symptoms exhibited by women are vague compared to men. From these it can examined that by doing repeated things and getting themselves drawn to the maximum in service acting has brought women to health hazards which shows that the capitalists not only exploit them but also drill them down and engage the health and mental state of these ladies to detriment.

\subsection{Conflict at work}

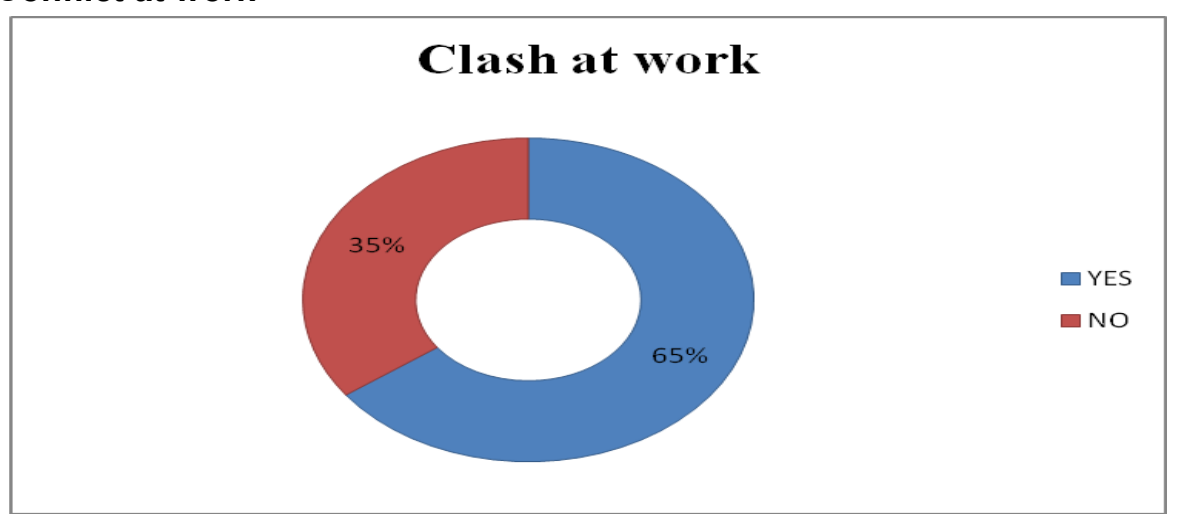

Figure 3.16 
From the pie chart, $65 \%$ was recorded which demonstrates that due to the internal emotional clashes of their very feeling and misbehaviours from customers' side, female employees does confront conflict at work. From the explanations given by the employees, it can be concluded that sometimes if clients do misbehave, the employees do not always try to self control their anger. It has been noted that due to lack of dignity of their work, at times employees do misbehave which validate the studies of Van Maanen and Kunda (1989) who elaborated on misbehaviour of employees and even more if they do not identify themselves with their work as conceptualized by Ashforth \& Humphrey (1993). This also shows that there are employees who do not know how to manipulate their emotions and engage into deep or surface act which confirms the research of Grandey (2000). Additionally, some respondents put forward that they have to control their very emotion and react to these situations diplomatically.

\subsection{Women and Work-Life Balance}

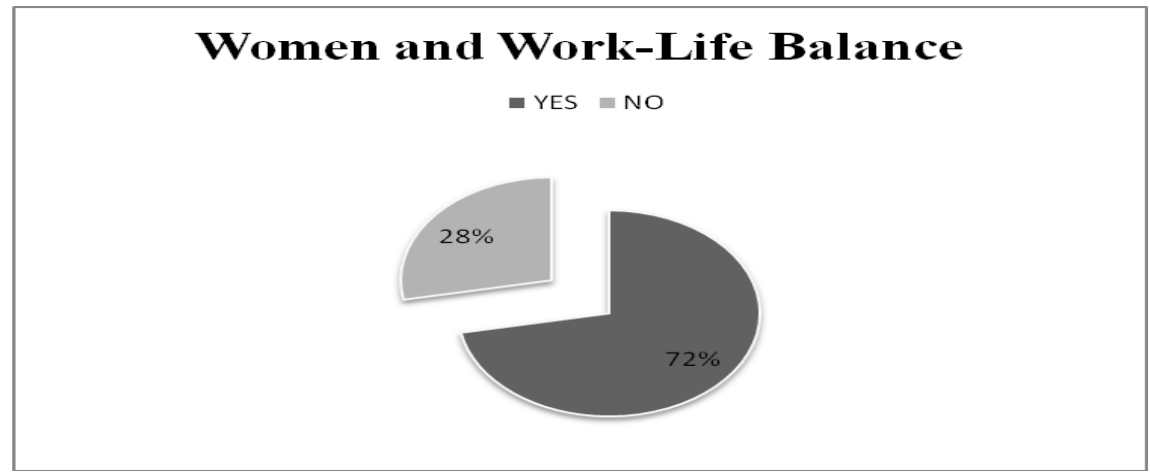

Figure 4.19

Studies till now have revealed the non-existence of a proper balance of the private and professional life of women.72\% accepted on the point that women's private lives are indeed affected by the jobs they perform. Here we can conclude that women still do face problems in finding a proper balance between the work and their private lives as they have to deal with both household chores and work responsibilities. These challenges can somehow contribute towards making women a much weaker being.

However, the human resource manager herself agreed on this fact that being a woman herself she does exhibits negative feelings at home due to her work, but she tries to keep a balance between both which validates what Hochschild (1989) stipulated through her work.

\subsection{Organisational Policies and Gender Issues}

From the diagram above, $\mathbf{7 3} \%$ are aware of the sexual harassment policy compare to the other two policies which gives an idea that in the hotel industry sexual harassment is a delicate issue which women have always been victims. It clearly illustrates that sexual harassment is a happening incident in the hotel industry which validates the research of both Biswas and Casell (1996) and Purcell.K (1996) as 
women are viewed as sexual entities. Moreover, there does exist a quite large number who are unaware of the policies of the organisation.

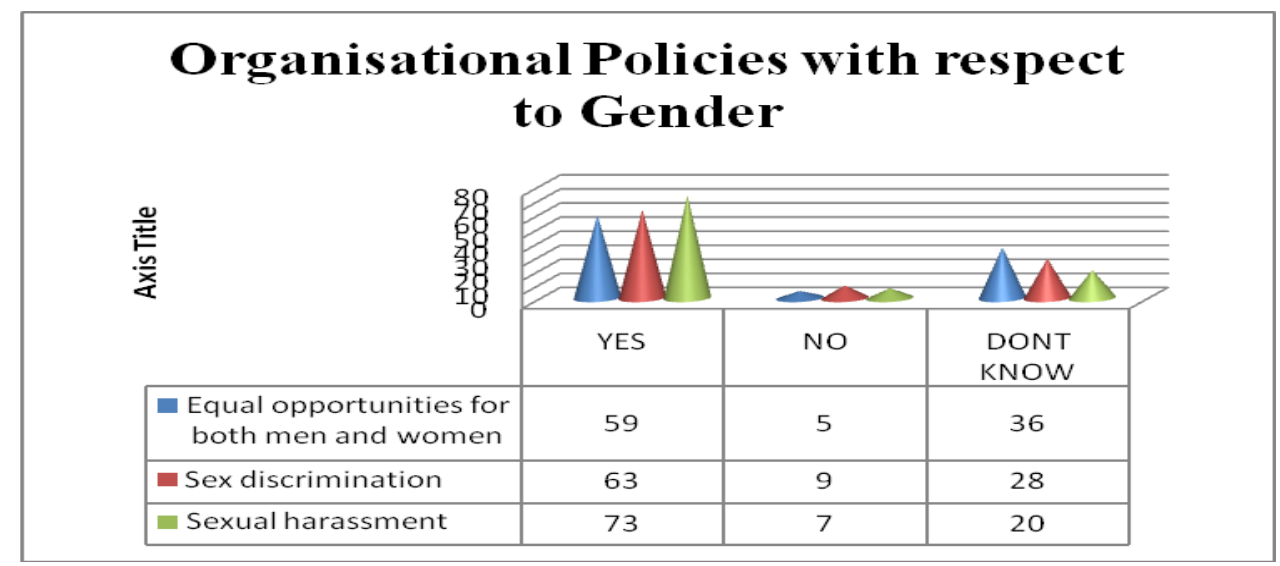

Figure 4.20

\section{Recommendations}

After the representation and analysis of the gathered data, it has been noted that the idea of emotion management has been implanted in the curriculum of work by the capitalists on the female workers. However, the dark side of the issue is that these women have a psychological cost to pay so as to meet the job prescriptions. Hence, a series of rational recommendations will be presented in order to improve the working conditions of these service actresses.

* Proper Division of labour

It has been noted that the problem of gender differences roots in the management itself, which means the distribution of work is not done on an equal basis. The management must equalize the number of employees performing emotional work not on the basis of gender differences but on an egalitarian platform; equal number of both males and females performing emotional labour.

* Flexibility and independence in performing emotional work By giving this little much of flexibility in performing their tasks, these service workers will feel a degree of autonomy and also the recognition that the top management trust their work will add to greater commitment in their performance. Being deeply engaged in deep and surface acting, these female employees will suffer from psychological problems and suffocation as well, therefore by giving them a little degree of freedom will be a positive act.

* Allocation of frequent holidays

With the Tayloristic forms of work, the allowance of holidays will be very beneficial for both the staffs and the hotel as well; because by having frequent 
holidays staffs will be less stressed and will be able to dedicate time to their family as well. Working women always complain of lack of family attention when they start working and by allocating holidays, this issue will be solved and thus the organisation will be able to secure emotional attachment from its employees as the staffs will feel a sense of caring from the organisation.

* Resourceful activities for staffs

Activities like stress management programs, more precisely the practice of yoga is recommended for the emotional labours. These kinds of activities will allow them to be more resourceful and find new avenues towards performing their work; thus exhibiting positive energies throughout the hotel.

* Better work schedule

It has been noted that the time allocated for interaction between the customers and the workers is very demanding and intense as it is the crucial moment for the workers to engage themselves in deep or surface acting. It would have been more interesting and for better customer satisfaction to have an increase in the rotation of staffs performing emotion management. For example, for every 3 hours all staffs performing highly emotional work get replace by new staffs that were not engage in emotional acting. This change will give freshness to the interaction and also it will relieve the workers from monotony and stress.

- Better treatment towards female employees

Female workers due to their stereotyped image and being part-time workers have always been downgraded at work. A more reasonable approach should be adopted by the management when it comes to female workers and their work schedule. They should be treated as "valuable assets" for the organisation and not as "pieces of objects" which are being used only for profit maximisation.

* Representatives for female workers at the top management level By having a representative of female workers at the management, will contribute towards making the upper level management aware of the dilemmas faced by women while performing their work and it will act as a facilitator for both the management and the employees when it comes to the flow of information as through the analysis phase it has been noted the lack of a spokesperson on behalf of the women.

* Placing women at all managerial level

There is a marginal representation of women in the hotel across all levels of management. This problem can be solved by giving more opportunities for women to take up challenging tasks and also trying to bring a new perception of the stereotyped picture of women. By placing women at all levels, the management will be able to identify the potentials of those women which will contribute towards the success of the organisation.

* Increase in salary and introducing reward system 
Women have always been treated as low wage workers and this opinion on them act as a de-motivating factor in their work performance. By increasing their wage will add as a sense of motivation to their daily work and also by introducing the reward system in the midst of their performance will operate as a medium to perform their work to the excellence as all of them will target the reward. It will be a way towards acknowledging their "talent" and working conditions as well.

* On site psychological support

From the information gathered in the analysis phase, it has been noticed that the hotel does not have any kind of on site psychological support for its workers. By introducing that in the managerial system, it will be a caring attitude from the management side as it has been observed that women do encounter psychological dilemmas while performing intense emotion management. This support will play an important facet in the whole dimension of the work life of women and their emotional dilemmas will be solved to a great extent and therefore they will be able to have a proper work-life balance.

* Less use of cameras

Furthermore, cameras are being used on a high scale which is an important factor for the security of the customers and the hotel as well; but on a deeper analysis we will find that those cameras does not encourage the true commitment from the employees and also the lack of trust from the management side. Therefore there must be an average number of cameras for the security of the customers and also making the employees aware that the cameras are placed mainly for the purpose of security.

* Better communication

It has been noted that some employees are not well aware of the policies present in the organisation. It is recommended a better flow of communication from the top managerial level to the low level management. Communication nowadays is being seen as a pillar for organisational success and by having this proper flow; the managers will be able to secure trust from its employees.

\section{Conclusion}

This study has aimed at demonstrating the realities of the world of work when it comes to emotion management and its direct relationship to female workers. It provides a deeper understanding of emotion management and its effects on female workers as women have always been subjected to discrimination when it comes to their working life. It has also explored the different dimensions of emotional work and emotional labour and its commercialisation process at the hotel.

Moreover, it is believed that the hospitality sector is a female dominated one; but the realities are far behind as the under representation of ladies noted at the hotel explains the fact that women are regarded as the weaker vessels and therefore manipulating them become easier for the capitalists and making them perform intense 
emotional labour. The normative ideology that the society has on women has contributed largely in making her victims of the type of roles they performed at home. Being always regarded as "caring", "nice" has stereotyped their roles and become victims of emotional labour.

As a conclusive note, this study has tried to find explanations on how and why women are mostly engaged in the commercialisation process of their very own emotions and also brought forwards the dilemmas associated to it. This study also provides constructive methods to enhance the present situation of women in the service sector. However, the question still arises "caring for emotional well being of women in the service sector will that be top the detriment of the male workers", "will the organisation be able to balance the right measure of the mode of work on the basis of genderless issue". These questions indeed take a different look of the whole issue and also require a deep thinking.

\section{References}

ACKROYD, S. And P. THOMPSON. 1999, Organizational Misbehaviour. London: Sage.

APPEL, M.A., HOLROYD, K.A. and GORKIN, L. 1983, "Anger and the etiology and progression of physical disease", in Temoshok, L., van Dyke, C. and Zegans, L. (Eds), Emotions in Health and Illness: Theoretical and Research Foundations, Grone \& Stratton, New York, NY, pp73-87.

ASHFORTH, B., \& HUMPHREY, R. 1995, Emotion in the workplace: A reappraisal. Human Relations, 48, pp97-125.

ASHFORTH, B.E. and HUMPHREY, R.H. 1993, 'Emotional labor in service roles: the influence of identity', Academy of Management Review, Vol. 18, pp88-115.

ASHFORTH, B.E, \& TOMIUK, M.A. 2000, Emotional labor \& Authenticity: Views from service agents. In S.Fineman (Ed.), Emotion in organizations (2 $2^{\text {nd }}$ Edition,); pp184-203. Thousand Oaks, CA: Sage

BELL, C. And NEWBY, H. 1976, "Husbands and wives: the dynamics of the deferential dialectic" in Baker, D.L and Allen S (Eds), Dependence and exploitation in work and marriage, Longman London.

BISWAS, R. And CASELL, C. 1996, 'Strategic HRM the gendered division of labour in the hotel industry: a case study,' Personnel Review, Vol. 25, No 2, pp19-34.

CONRAD, C. \& WITTE, K. 1994, Is emotional expression repression oppression? Myths of organizational affective regulation. In S. A. Deetz (Ed.), Communication Yearbook, 17 pp 417-428. Thousand Oaks, CA: Sage.

10) DAVID, M., and WOODWARD, D., (Eds). 1998, Negotiating the Glass

Ceiling: Careers of Senior Women in the Academic World. London,

Falmer Press.

ERICKSON, R.J. and WHARTON, A.S. 1997, 'Inauthenticity and depression: assessing the consequences of interactive service work', Work and Occupations, Vol. 24, pp188-213.

ETZIONI, A. 1969, The semi-professions and their organization: teachers, nurses, social workers New York: Free Press

FOUCAULT, M. 1977, Discipline and Punish, Pantheon Books, New York.

FOUCAULT, M. 1991, Discipline and Punish, Penguin Books, Harmondsworth.

FRIEDL, E. 1975, Women and Men - an anthropologist"s view, Waveland Press Inc. 
FRIJDA, N. H. 1994, Emotions are functional, most of the time. In P.Ekman \& R. J. Davidson (Eds.), The nature of emotions: Fundamental questions pp112-122. New York: Oxford University Press.

GABRIEL, Y. 1988, Working lives in catering, Routeledge and Kegan, Paul: London.

GRANDEY, A. 2000, Emotion regulation in the workplace: A new way to conceptualize emotional labor. Journal of Occupational Health Psychology, 5(1): pp95-110.

GROSS, J. J., \& JOHN, O. P. 2003, Individual differences in two emotion regulation processes: Implications for affect, relationships, and well-being. Journal of Personality and Social Psychology, 85, pp348-362.

HOCHSCHILD, A. 1983, The Managed Heart: Commercialization of human feeling. Berkeley: University of California Press.

HOCHSCHILD, A. 1989, The Second Shift, Avon, New York 1989.

ISENBARGER, L., ZEMBYLAS, M. 2006, "The emotional labour of caring in teaching", Teaching and Teaching Education, Vol. 22 pp120-34.

JAMES, W. 1884, What is an emotion? Mind, 9, pp188-205.

JAMES, W. 1950, The principles of psychology, Volume II, Chapter 25: The emotions pp442485. NewYork: Dover. (Original work published 1890)

JAMES, W. 1994, The physical basis of emotion. Psychological Review, 1, pp516-529.

KNUTSTON, B.J. \& SCHMIDGALL, R.S. 1999, Dimensions of the glass ceiling in the hospitality industry. The Cornell Hotel and Restaurant Administration Quarterly 40(6), pp64-75.

MAAN, S. 2004, 'People-Work': emotional management, stress and coping. British Journal of Guidance and Counselling, 32(2), pp205-221.

MAAN, S. 2007, "Expectations of emotional display in the workplace, An American/ British comparative study", Leadership \& Organization Development Journal, Vol. 28 No. 6 , pp552-570.

MARSHALL, J. 1995, Women Managers Moving On. London, Routledge.

MORRIS, J.A. And FELDMAN, D.C. 1996, "The dimensions, antecedents, and consequences of emotional labor”, Academy of Management Review, Vol. 21, pp986-1010.

NICOLSON, P. 1996, Gender, Power and Organisation, London: Routledge.

OAKLEY A 1994, Who cares for health? Social relations, gender, and the public health. $J$ Epidem Comm Health 48, pp427-434.

PERSAUD, R. 2004, Faking it the emotional Labour of Medicine. StudentBMJ, Vol 12, pp309348.

PUGH, S.D. 2002, Emotional regulation in individuals and dyads: Causes, costs and consequences. In R.G. Lord, R.J. Klimoski, \& R. Kanfer (Eds), Emotions in the workplace. San Francisco, CA: Jossey-Bass.

PURCELL, K. 1996, 'The relationship between career and job opportunities,' Women in Management Review, Vol. 11, No. 5, pp17-24.

RAFAELI, A. and SUTTON, R.I. 1987, 'Expression of emotion as part of the work role', Academy of Management Review, Vol. 12, pp23-37.

ROBSON, C. 2002, Real World Research, $2^{\text {nd }}$ ed., Oxford: Blackwell

ROSE, N. 1991, Governing the Soul: The Shaping of the Private Self, Routeledge, London.

SAYER, A. 2007, Organisation. Dignity at work: Broadening the Agenda, Sage publications.

VAN MAANEN, J., And KUNDA, G. 1989, "Real feelings; emotional expression and organizational culture", in Cummings, L.L and Staw, B.M. (Eds), Research in Organizational Behavior, Vol. 11, JAI Press, Greenwich, CT, pp43-103.

VAN MAANEN, J., And KUNDA, G. 1989, "Real feelings": Emotional expression and organizational culture, Research in Organizational Behavior, 11, pp43-103. 
WALDRON, V. R. 1994, Once more, with feeling: Reconsidering the role of emotion in work. In S. A. Deetz (Ed.), Communication Yearbook, 17, pp 388-416. Thousand Oaks, CA: Sage.

WHARTON, A. 1993, The affective consequences of service work. Work and Occupations.

WHARTON, A. S. 1993, The affective consequences of service work: Managing emotions on the job. Work and Occupations, 20(2), pp 205-232.

WHARTON, A. S., \& ERICKSON, R. J. 1993, Managing emotions on the job and at home: Understanding the consequences of multiple emotional roles. Academy of Management Review, 18, pp 457-486.

WHARTON, A. 2004, The sociology of gender - An Introduction to theory and research, Wiley Blackwell publishing, New York, NY.

Reports

ILO Report, 1998

CSO Report, 2009

Equal Opportunity Act 2009 